\title{
O ENSINO DE HISTÓRIA E A HISTÓRIA LOCAL: EXPERIENNCIAS DE PESQUISAS DESENVOLVIDAS POR ALUNOS DO ENSINO MÉDIO NA CIDADE DE VIÇOSA (MG)
}

Raquel dos Santos Sousa Lima*

RESUMO:

O ohjetivo desse artigo é apresentar a experiência da recuperação da história local desenvolvida junto a alunos da segunda série do Ensino Médio do Colégio Universitário de Viçosa. Como intuito de propiciar aos alunos uma interação entre o conteúdo estudado durante o ano e a realidade à sua volta, desenvolvemos um trabalho em que eles pesquisaram os grupos de imigrantes, os sindicatos, os partidos políticos e os movimentos sociais da cidade. Os trabalhos produzidos por eles resultaram em fotos, registros de depoimentos, gráficos, tabelas, cartazes e filmes, fazendo do ensino de história algo mais interessante e sobretudo significativo, já que puderam compreender melhor a comunidade que os cerca, além de incentivá-los como sujeitos ativos da história e como produtores de conhecimento histórico.

UNITERMOS: Ensino de História, História local, pesquisa.

A idéia de se fazer um trabalho com os alunos da segunda série do ensino médio do COLUNI surgiu a partir da vontade de propiciar a eles uma interação com sua realidade social mais imediata, de forma a levá-los, também, a um trabalho de análise e reflexão que os permitisse compreender a forma como o conhecimento histórico é produzido. Assim, os objetos

" Graduada em História e Especialista em Ciência da Religião. Professora de História no Colégio Universitário de Viçosa - UFV. 
propostos para a pesquisa foram selecionados de maneira que permitissem una integração do conteúdo de história trabalhado na respectiva série durante o ano - o século XIX como momento de consolidação do capitalismo - e alguns aspectos relacionados à história de Viçosa. Desta forma foram escolhidos os seguintes temas, todos relativos à cidade: a formação dos partidos políticos, os sindicatos existentes, os grupos de imigrantes e os movimentos sociais da Igreja Católica.

O trabalho realizado pelos alunos viria ainda como parte de uma nova proposta para o processo de ensino-aprendizagem em história, que tradicionalmente é voltado com intensidade à transferência de conhecimentos contidos nos livros didáticos, originando um "tipo de ensino que enfatiza um saber pronto e acabado, cujo desdobramento é a aversão à reflexão e ao criticismo e à falta de comunicação pois, na maioria das vezes, a aula é centrada na fala do professor"!.

Procuramos então fugir desse tipo de ensino que é ligado ao eixo transmissão-assimilação de conteúdos, feito geralmente pela memorizaçãa de datas, nomes e fatos e partir para um tipo de experiência inovadora, mais prazerosa para os alunos e que pudesse "desempenhar um papel importante na configuração da identidade, ao incorporar a reflexão sobre a atuação do indivíduo nas suas relações pessoais com o grupo de convívio, suas afetividades, sua participação no coletivo e suas atitudes de compromisso com classes, grupos sociais, culturais, valores e com gerações do passado"', como enfatizam os Parâmetros Curriculares Nacionais.

O trabalho com a história local se constituiu, então, como uma possibilidade teórico-metodológica ideal para desenvolver

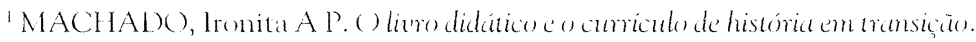
P'asso Fundo: Ediupf, 1999. p. 215.

¿ BRASIL. MLC/SEM. Parâmetros curriculares nacionuis: ensino médio. Brasília: MEC, 1999. p. 301.
} 
no aluno as habilidades de pesquisa, síntese, compreensão e transmissão do conhecimento sobre determinada realidade, mais próxima. Procurou-se trabalhar com os alunos a concepção de que a história regional e local não são reflexos fiéis da história nacional, mas que "sempre é o resultado de uma interação reciprocamente determinante de forças locais e globais cuja lógica deve primeiro ser compreendida em seus próprios termos; é melhor conceituada como o reflexo de uma dialética de articulação entre um sistema local e o contexto em que o mesmo se insere, ou seja, à luz de como as formas internas e as forças externas condicionam-se mutuamente"3.

Trabalhar com a história regional implica analisar uma determinada singularidade em meio a uma totalidade, sob um "movimento dialético entre a micro-história e a macro-história, para não cair no erro de relativizar os acontecimentos, idealizando grupos e acontecimentos"4. Enfatizamos, portanto, a análise de experiências de determinados grupos sociais em Viçosa de maneira a articulá-los com o conteúdo visto em sala de aula. Partindo de aulas expositivas e leituras que forneceram um embasamento teórico para os alunos tentamos enquadrar alguns aspectos da sociedade européia e brasileira durante o século XIX e vinculá-los com o presente, para que o aluno identificasse essas relações de continuidade ao seu redor. É claro que essas relações não são diretas e é necessário ter o cuidado de não transpor anacronica e geograficamente certas questões.

É necessário ressaltar ainda que o conceito de história local apenas norteou a iniciativa do trabalho, uma vez que pretendese dar continuidade a ele, já que várias interrogações surgiram

\footnotetext{
'HUNT, Loyhh. A non'c histríma cultural. São Paulo: Martins Fontes, [19--] . p. 126. + MACHADO, Ironita A P. O linro didático e o currículo de história em transição. Passo Fundo: Ediupf, 1999. p. 213.
} 
durante a pesquisa e que, em função do tempo previsto a princípio, ficaram para depois.

Consideramos conveniente apresentar a metodologia aplicada em dois trabalhos, como uma mostra das formas adotadas pelos alunos na elaboração da pesquisa, conclusão e apresentação. Como a exposição das experiências com todos os temas extrapolaria nosso tempo, escolhemos Os Imigrantes em Viçosa e Os Sindicatos em Viçosa, já que eles são os mais próximos do conteúdo estudado durante o ano letivo.

\section{Imigrantes em Viçosa}

A escolha desse tema se deu em função do estudo do início da imigração para o Brasil, por volta dos anos de 1870 , como parte do planejamento do ensino de história adotado pelo colégio. Partimos daquela situação específica, como eixo original para se entender a entrada de estrangeiros no país e procuramos, na comunidade de Viçosa, encontrar os principais grupos de imigrantes. A partir de nomes sugeridos pelo professor, bem como dayueles yue os próprios alunos conheciam como fruto de suas relações sociais, eles entraram em contato com essas pessoas. Vale observar que foram encontrados tanto comunidades de imigrantes, como vários estudantes estrangeiros que estavam na cidade apenas de passagem, em função dos intercâmbios da Universidade Federal com outros países, sobretudo latinos. Em alguns casos esses estudantes também foram contatados, já que despertavam um grande interesse nos alunos por conviverem num mesmo espaço físico, o Campus Universitário. A maioria dos trabalhos com eśse tema aliou a bilbliografia encontrada sobre o assunto com entrevistas ${ }^{5}$ realizadas a partir de perguntas ${ }^{0}$ elaboradas pelo grupo(de oito alunos) e que iam desde o motivo impulsionador da vinda para 
Viçosa até as curiosidades e dificuldades encontradas por eles. Um grupo de alunos da segunda série D realizou quatro entrevistas interessantes. Uma delas foi com um pastor da Igreja Preshiteriana, que veio para o Brasil "porque a Igreja Evangélica estava crescendo muito e senti que Deus estava me chamando para ser mais um discípulo a pregar a Bíblia" ${ }^{2}$. De acordo com o relato dos alunos, foi valioso observar na fala do imigrante como um motivo religioso forçou a adaptação desse pastor inglês na sociedade brasileira, levando-o a experienciar mudanças sócioeconômicas inimaginadas, que terminaram por baixar o seu padrão de vida. Além disso, eles constataram a influência externa do fenômeno da expansão das igrejas evangélicas como algo típico do panorama religioso brasileiro.

Entrevistaram também um casal libanês que veio para o Brasil em 1955, bem como outros descendentes de libaneses que aportaram em Viçosa desde a época da Primeira Guerra Mundial e constituíram uma forte comunidade, dedicando-se principalmente às atividades comerciais.

Ainda foram encontrados alemães e italianos, que também vieram para o país durante as guerras mundiais, chamando atenção o caso de alguns que vieram com destino ao trabalho em cafezais da Zona da Mata Mineira e que, "ao passarem por Viçosa, gostaram tanto da beleza da cidade"s, que nela resolveram ficar.

Há também o caso dos estrangeiros itinerantes, isto é, aqueles que estão em Viçosa por causa da Universidade. Num levantamento realizado junto ao Registro Escolar da UFV, os

\footnotetext{
" deve-se ohservar que os alumos não desenvolveram um trabalho de Histriria Oral, mas apenas se utilizaram da entrevista como um instrumento de pescpuisa.

- Ver Anexo I no final do trabalho $\mathrm{com}$ as principais perguntas elaboradas pelos alunos sobre a imigração.

Entrevista dada pelo pastor Andrew John Buxton aos alunos (la turma 2D)/ 2000, COLUNI.

"Ver trabalho Inigraçäo em Viçosa, turma 2D/2000, COLUNI.
} 
alunos constataram que no ano de 2000, do total de estudantes de Graduação 04 eram da América do Sul, 05 da América Central e Caribe e 21 de países africanos, estes em sua maioria de língua portuguesa. Quanto aos estudantes da PósGraduação, 26 eram da América do Sul, 07 da América Central e 41 da África. Nas entrevistas, o grupo observou que em geral eles vêm através dos convênios realizados com a UFV, sobretudo na área de ciências agrárias, no intuito de conhecer e principalmente aperfeiçoar novas tecnologias a fim de levar o desenvolvimento para seus países de origem.

De acordo com o relato dos alunos foi interessante conhecer as principais dificuldades adaptativas desses estrangeiros, sobretudo no que tange à questão cultural, como alimentação, idioma, moradia, hem como aquilo que eles consideram exótico em nossa sociedade - o convívio próximo entre as pessoas, as relações de vizinhança e "o jeito de dançar, essa coisa de Popozuda, as festas" ${ }^{\prime \prime}$, tão comuns aos nossos jovens, mas tão diferentes para os outros.

A maioria dos trabalhos sobre os estrangeiros em Viçosa foi realizada a partir de entrevistas, variando, porém, a forma de apresentação. Nesse aspecto, os alunos souberam utilizar bem os recursos audio-visuais, fotografando, gravando entrevistas e até levando objetos pessoais dos entrevistados, tendo destaque um grupo que mandou editar uma fita com os trechos considerados mais adequados para eles, tornando a apresentação atraente para o resto da turma.

Entre os temas propostos para a pesquisa, este acabou se destacando, muito em função da novidade- do outro-, tão perto deles e ao mesmo tempo tão distante da realidade brasileira. Além

\footnotetext{
"Entrevista do professor David Joseph Nemcok, americano que se radicou em Viçosa, alos alunos da turma 2C.
} 
disso, como conclusão geral dos quatro trabalhos feitos, eles observaram que, apesar dos diferentes contextos que impulsionaram nacionalidades diversas para a cidade, a maioria das pessoas reclamou do custo de vida no país, das dificuldades financeiras, de emprego, da falta de responsabilidade do estado brasileiro para com a saúde e a educação, excetuando-se neste caso os estudantes que vieram da África, movidos por guerras civis e que por isso viam nas bolsas de estudo uma ótima possibilidade de realização pessoal.

Como uma análise do ponto de vista do professor, consideramos os resultados apresentados pelos alunos como positivos, uma vez que eles atingiram o objetivo de conhecer um pouco mais de sua própria história e das relações sociais existentes na comunidade em que vivem, conseguindo articular os motivos internos e externos que impulsionaram a imigração para o Brasil no século XIX, com a identificação de grupos que aportaram em sua cidade, num contexto bem diferente daquele mas, às vezes, por motivos ou interesses bem parecidos com os do passado. Assim, esperamos ter contribuído para o processo de aprendizagem de forma mais ativa e participativa para o aluno permitindo que, na construção do conhecimento histórico, ele reconheça as interações passado-presente.

\section{Os Sindicatos em Viçosa}

A proposta de se realizar um levantamento dos principais sindicatos encontrados na cidade de Viçosa partiu da intenção) de articulá-los a determinados conceitos vistos pelos alunos quando estudavam o início do movimento operário europeu. Partimos do conceito de que o sindicalismo era um fenômeno relacionado ao surgimento da classe dos trabalhadores assalariados, 
no momento em que a ordem capitalista se legitimava na segunda metade do século XIX, nos países mais industrializados.

Como etapa inicial, sugerimos uma bibliografia básica aos alunos e solicitamos que eles trabalhassem com um conceito específico sobre o sindicalismo, para que depois iniciassem as pesquisas. A escolha dos sindicatos que seriam analisados ficou por conta dos grupos. Porém, exigimos que eles levantassem os nomes de todos aqueles encontrados, tarefa que não foi muito difícil, uma vez que a cidade é pequena.

No geral, eles trabalharam com a noção de que o sindicalismo pode ser definido como uma "ação coletiva para proteger e melhorar o próprio nível de vida por parte de indivíduos que vendem sua força de trabalho"10 e que o sindicato "é a associação de trabalhadores assalariados de determinado setor econômico que tem a função de defender ou melhorar as condições do contrato de trabalho, mediante pressão sobre os empregadores ou o estado" $"$.

Logo de início, os alunos perceberam que a presença de sindicatos em Viçosa se restringia a poucas associações de trabalhadores, sendo que as mais fortes estavam ligadas à área de educação è Universidade Federal, uma vez que a cidade gira em torno dela, já que não tem um pólo industrial forte.

Assim, passaram à etapa seguinte, sendo que a maioria dos trabalhos privilegiou as entrevistas ${ }^{12}$ com membros e presidentes da Seção Sindical dos Docentes da UFV (ASPUV) e Associação dos Servidores Administrativos da UFV (ASAV). O grupo da segunda série A conseguiu também demonstrar

\footnotetext{
12 Ver traballio Os sindicatos em Viçosa, turma 2C/2000, COLUNI.

"Ver trabalho Os sindicatos em Viçosa, turma 2B/2000, COLUNI.

12 Ver Anexo Il no final do trabalho com as principais perguntas elaboradas pelos alunos sobre o sindicalismo.
} 
como ocorreu a formação de um sindicato de servidores da Universidade, o Sindicato dos Servidores da UFV (SINSUV), que surgiu a partir de divergências com a ASAV. Para os alunos este foi um dado muito interessante pois, se os sindicatos mais fortes estavam vinculados à Universidade, como se explicava o aparecimento de uma dissidência política entre a representação dos servidores de uma mesma instituição? Com essa interrogação eles descobriram que o SINSUV ${ }^{13}$ tem cerca de 2200 associados, dos quais 1500 contribuem $\mathrm{com} \mathrm{0,5 \%} \mathrm{do}$ salário, ahrangendo cerca de $60 \%$ dos funcionários da UFV. Este sindicato, apesar de participar de movimentos de resistência tais como greves e reivindicações salariais, tem atuado mais como um órgão de assistência social ao servidor oferecendo xerox, tratamento odontológico mais barato, descontos em supermercados, açougues e escritórios de advocacia e contabilidade. Quanto à $\mathrm{ASAV}^{14}$, o número de associados é de 3200 pessoas, que pagam a mensalidade de 1\% do salário bruto. Essa associação é filiada à CUT através da FASUBRA, o yue foi apontado pelos alunos como o aspecto que a diferencia substancialmente da SINSUV, tornando-a um órgão mais politizado. Mesmo oferecendo atividades recreativas, sociais e henefícios como a outra, ela participa mais ativamente dos movimentos nacionais de resistência ao governo, tendo obtido importantes conquistas nos quadros administrativos da UFV, tais como a criação de laboratórios de informática, a creche universitária, a compra de ambulâncias e vários cursos de capacitação e alfabetização.

Os trabalhos constataram que os primeiros sindicatos em Viçosa surgiram como associações que tinham o objetivo de promover atividades de lazer para os associados e que foram

"Data de fundação de 03 de janeiro de 1990.

1.t Data de fundação de 26 de junbo de 1984. 
tomando um perfil diferente com o tempo, se aproximando mais do conceito real de sindicalismo. Além dos sindicatos acima citados, encontraram o Sindicato dos Funcionários da Prefeitura Municipal, o Sindicato de Trabalhadores nas Indústrias da Construção e o Sindicato de Produtores e o dos Trabalhadores Rurais de Viçosa. Estes quase não têm força política na comunidade, sobretudo o de trabalhadores rurais (incluindo algumas cidades da região) uma vez que os assuntos relacionados a esse campo são tratados pelas cooperativas rurais. Destaca-se, porém, o Sindicato Único dos Trabalhadores em Educação/MG com um importante papel político e força na luta sindical travada em nome da categoria.

De acordo com o relato dos alunos o trabalho foi válido pois eles puderam entender a importância dos sindicatos na vida da classe trabalhadora em prol de seus direitos trabalhistas, bem como da curalidade de vida e perceber as dificuldades encontradas por esses órgãos em sua afirmação como categoria frente ao governo. Vários alunos ainda contaram a surpresa de saber que determinados ganhos e conquistas sociais e até esportivas da cidade se deram a partir da luta de tais sindicatos. Além dissoso, se conscientizaram da necessidade de uma reflexão constante e geral sobre os grandes problemas do país, especificamente aqueles relacionados à área de educação, no intuito de garantir o tão propalado refrão de "luta por uma escola pública, gratuita e de qualidade"15.

\section{Resultados e conclusão: Uma avaliação do trabalho}

Concluídas as etapas de pesquisa, elaboração e apresentação dos trabalhos pelos grupos, partimos para a

\footnotetext{
is Aspectos ressaltados pelos alunos da turma 2 A na entrevista concedida pelo Prof. José Dionísio Ladeira, secretário de divulgação da ASPUV.
} 
avaliação. Em termos quantitativos, o trabalho foi valorizado em 6 pontos, sendo distribuídos de acordo com os seguintes critérios: apresentação oral, com todos os membros do grupo, envolvendo criatividade na utilização dos recursos e dinâmica, devendo relatar o processo inicial da pesquisa, explicitando as fontes e dificuldades encontradas; trabalho escrito, constando a hihliografia e os aparatos teóricos; ter mantido contato com o professor durante a pesquisa; a consistência das informações obtidas de acordo com o tema e suas relações com o conteúdo estudado em sala de aula.

En termos qualitativos e, do ponto de vista do professor, consideramos os resultados extremamente positivos, uma vez que a maioria dos grupos se dedicou efetivamente ao trabalho, produzindo fotografias, cartazes, trabalhos escritos consistentes e inclusive vídeos, nos quais estava perceptível a relação que os alunos conseguiram estabelecer entre sua realidade imediata e o conteúdo estudado durante o ano.

No entanto, acreditamos que a avaliação geral dessa nova proposta para o processo de ensino-aprendizagem não deveria ser feita apenas pelo professor, para não correr o risco de ser parcial, forçando a barra para encontrar nas apresentações dos alunos as respostas que atingissem os seus objetivos. Assim, elaboramos um questionário ${ }^{16}$ e os enviamos aos alunos, para que eles fizessem uma avaliação da proposta feita pelo professor. Perguntamos o que eles acharam dos temas selecionados, que tipo de recursos utilizados foram mais interessantes como instrumento de pesquisa, se o trabalho enriqueceu os conhecimentos sobre a história de Viçosa e, ainda, se deveríamos aplicá-los aos alunos das segundas séries. Para finalizar, pedimos que apontassem críticas ao trabalho do professor.

Depois de recebermos as respostas passamos à etapa de tabulação e sistematização dos dados. Constatamos que $83,78 \%$

"Ver Anexo III no final do trabalho com o questionário enviado aos alunos. 
dos alunos consideraram o tipo de trabalho e os temas abordados como sendo interessantes e apenas 3\% acharam chatos. Além disso, eles escolheram as entrevistas como os melhores recursos utilizados durante a pesquisa e apresentação, seguidas da fotografia, do vídeo, da pesquisa billiográfica, da teatralização e da confecção de cartazes. Com base nesses dados, pudemos confirmar que alguns de nossos objetivos iniciais, no que tange a novas propostas de ensino-aprendizagem começaram a ser atingidos.

Perguntados ainda se esse tipo de trabalho deveria ser aplicado aos alunos das outras séries, $89 \%$ deles responderam que sim, contra 0,8\% que foram contrários. Entre as justificativas dadas nessa resposta, encontramos desde "sim, eles devem fazer porque nós fizemos" iz até "sim, pois é uma outra forma de aprender que ajuda a gravar melhor, quando é bem feita". Outros disseram cue foi uma boa oportunidade "de conhecer melhor a história local, podendo relacioná-la num contexto maior" e "para formar o cidadão local, sabendo o que foi feito no passado para construir um bom futuro". De posse dessas respostas começamos a vislumbrar a constatação daquilo que supúnhamos antes, isto é, de que o ensino de história local permite ao aluno uma interação maior com o seu ambiente sócio-histórico. E, se esse ensino parte do pressuposto de que o aluno tem uma participação ativa na construção do conhecimento, fica mais fácil entender que para ele, " esse tipo de trabalho deixa o conteúdo visto em história menos teórico e, conseqüentemente, mais didático, mais interessante". É claro que encontramos respostas negativas, onde a principal justificativa foi o fato de serem grandes e trabalhosos, que requerem muito tempo e, "por serem temas diferenciados, poderiam ser abordados através de palestras". Algo porém, nos

\footnotetext{
i Os trechos destacados que vêm a seguir foram retirados das várias respostas dadas pelos alunos no yuestionário proposto pelo professor.
} 
chamou a atenção, quando uma aluna afirmou que "os conhecimentos adquiridos nesses trabalhos não são passados como conteúdo pelos professores". Interpretamos tal resposta como uma observação da aluna sobre a falta de abordagem, dentro dos currículos oficiais e dos programas estaduais de ensino, da utilização da história local como algo que torna mais acessível o conhecimento da sua realidade pelo próprio aluno, no intuito de "conhecerem melhor e ter visão crítica".

Foi necessário, ainda, saber dos alunos se o trabalho proposto pelo professor tinha enriquecido os seus conhecimentos sobre a história de Viçosa e de que maneira. Contabilizando as respostas, vimos que $62 \%$ dos alunos responderam que $\mathrm{sim}$, enquanto $37 \%$ acharam que pouco, sendo que nenhum deles optou por muito pontoo ou nada. No geral a justificativa dada por acpueles que responderam sim era de que ele ajudou a ampliar o conhecimento sobre os assuntos propostos, bem como a "enriquecer os meus conhecimentos não só da região, mas proporcionou uma maior assimilação dos processos imigratórios como um todo, já que as entrevistas foram muito ricas". Para alguns alunos que eram de outras cidades e, portanto, não conheciam quase nada sobre Viçosa, o trabalho foi hom pois "entrevistei pessoas diferentes, com outras idéias, outras culturas, modo de vida muito diferente, o que me enriqueceu". Há também aqueles que acharam o trabalho chato pois "o aluno que não mora em Viçosa não se interessa em saber sobre a cidade". Surpreendeu-nos, no entanto, quando lemos que o trabalho "ajudou a matar minha curiosidade em saber o que leva pessoas a virem para o Brasil e o que elas achavam. Além disso, observei o claro afloramento nacionalista em mim e em meus colegas". Esperávamos encontrar respostas que mostrassem a importância da história local para os alunos, mas não tínhamos pensado, até então, que ter contato com estrangeiros pudesse "aflorar o 
nacionalismo em mim", quando se sabe que esse "mim” é um aluno de dezesseis anos.

Para finalizarmos nossa avaliação, pedimos aos alunos que apontassem críticas aos trabalhos sugeridos pelo professor. Essa talvez tenha sido a parte mais interessante para nós, uma vez que foi uma forma de nos reavaliar, tendo um feed back do nosso desempenho enquanto professores-educadores. E foi oportuno observar que muitos deles tiveram bastante seriedade na análise e crítica àyuilo que não gostaram no professor e também ao que ficou a desejar por parte deles próprios.

A mais comum das reclamações foi o pouco tempo que tiveram para realizar toctas as etapas de pesquisa, sobretudo no "colégio onde a demanda de carga horária para estudar é alta e por isso o professor deveria dar mais parâmetros - fontes, apoio, orientação". Esta é uma observação extremamente válida pois vimos que, apesar dos trabalhos em sua maioria terem sido interessantes para eles, talvez teria sido mais proveitoso se tivéssemos reduzido os temas e nos dedicado mais à orientação. Por outro lado, entendemos essa estranheza dos alunos ao fato de terem de buscar sozinhos as suas fontes e informações, principalmente porquue dependem da "boa vontade de terceiros que nem sempre estão dispostos a fornecer informações". Aí constatamos mais uma vez que o ensino de história tem ocorrido, em grande parte, de forma tradicional, onde o aluno é colocado como mero receptor dos conhecimentos expostos pelo professor e que, quando propomos uma nova metodologia para o aprendizado, eles se sentem perdidos, já que não estão habituados com o papel de sujeitos ativos do seu próprio conhecimento. Outros reclamaram da falta de comprometimento dos grupos como um todo, já que foram grandes - oito alunos em cada grupo, o que teria prejudicado a qualidade dos trabalhos realizados, tornando as "apresentações às vezes insuficientes 
para se aprender mesmo", sobretudo no último bimestre. Mais uma vez, percebemos que nesse momento a atuação do profissional como orientador que vai complementar o trabalho é de fundamental importância e que os alunos sentiram a necessidade de "fazer uma aula só com debates com os alunos sobre os resultados", para que eles compreendessem melhor os critérios adotados na avaliação e fizessem essa ponte passadopresente de modo mais claro.

De posse de todas essas questóes, acreditamos ter alcançado a nossa meta inicial, uma vez que "através de temas atuais, com entrevistas, vídeos e pesquisas" "pude ampliar a minha visão social e populacional de Viçosa", fazendo um "paralelo Viçosa/Minas Gerais/Brasil/Mundo". Outros, falando dos sindicatos, afirmaram que "adquiri mais conhecimento sobre eles, como lutam pelos 'nossos' (sic) direitos e os obstáculos que encontram para o desenvolvimento de um trabalho consciente, que deseja melhorar a nossa vida". Constatamos que eles conseguiram fazer uma analogia dos temas estudados com a sociedade em que viviam, de maneira mais agradável e prazerosa para alguns, desinteressante e chata para outros poucos mas que, no geral, permitiu a eles ter uma visão mais crítica do processo histórico como um todo. E, finalmente, como já esperávamos, confirmamos que há uma necessidade urgente de mudanças nas concepções e sobretudo na prática do ensino de história, "partindo-se do presente, daquilo que representa o interesse e as necessidades dos alunos, em direção ao passado, na busca da explicação [...] através de um movimento dialético entre presentepassado-presente e na aprendizagem geral-específico/específicogeral, tornando-se significativa, capaz de mudanças sociais" ${ }^{\text {. }}$.

"MACHADO), Ironita A P'. O livero didático e o currículo de histónia em transiçäo. Passo Fundo: Ediupf, 1999. p. 225. 


\section{Bibliografia}

BRASIL. MEC/SEM. Parametros carriculares nacionais: ensino médio. Brasília: MEC, 1999. p. 301.

CABRINI, C. et ul.. O ensino de história: revisão urgente. 5. ed. São Paulo: Brasiliense, 1994.

HUNT, L. Anorch históricucultural. São Paulo: Martins Fontes, [19--]. p. 126.

MACHADO, I. A. P. O livro didático e o cumiculo de história em transição. Passo Fundo: Ediupf, 1999.

NADAI, E. O ensino de história no Brasil: trajetória e perspectivas. Revista Brasileira de História, São Paulo: v. 13, n. 25/26, p. 143-162, set. 1992/ago. 1993.

NIDELCOLFF, M. T. A escola e a compreensão da realidade. São Paulo: Brasiliense, [19--].

NUNES, S. doC. Concepçóes de mundo no ensino de história. Campinas, SP: Papirus, 1996.

PINSKY, J. (Org). O ensino de históric e a criação do fato. São Paulo: Ed. Contexto, 1994.

ABSTRACTS:

This article aims to present the local history rescue experience developed with the second year high school students from the UFV's High School (COLUNI). Intending to provide students an interaction between the subject studied during the year and the reality around them, we developed a work in which they researched the imigrant groups, the syndicates, the political parties and the social movements in the city. The works performed by them resulted in pictures, reports, graphics, tables, boards and films. This way, History teaching became something more interesting and mostly significant, once they could better comprehend the community that surrounds them, besides being motivated as active history characters and as historian knowledge producers.

KEY WORDS: History-teaching, Local History, Research. 


\section{ANEXO I - PRINCIPAIS PERGUNTAS ELABORADAS PELOS ALUNOS QUE TRABALHARAM O TEMA "IMIGRANTES EM VIÇOSA"}

- Nome, nacionalidade, idade

- O yue fazia no país de origem?

- Qual o motivo da vinda para o Brasil? E para Viçosa?

- O que faz hoje no país?

- Qual era a imagem que tinha do Brasil e de Viçosa?

- Há quanto tempo reside no Brasil? E em Viçosa?

- Veio em comunidade, com a família ou sozinho? Por quê?

- Qual foi a primeira impressão ao chegar no país e na cidade?

- Como foi a trajetória até chegar aqui?

- Teve alguma assistência ao chegar acjui?

- Como foi o período de adaptação?

- Quais foram as maiores dificuldades?

- O que achou mais exótico na cultura brasileira?

- Se arrependeu de ter vindo para o Brasil? E para Viçosa?

- Ainda tem contato com sua cultura?

- Do que sente mais falta?

- Pretende voltar a seu país de origem? Quando? Para quê? 


\section{ANEXO II - PRINCIPAIS PERGUNTAS ELABORADAS PELOS ALUNOS QUE TRABALHARAM O TEMA "SINDICATOS EM VIÇOSA"}

- Nome do sindicato

- Comor e yuando foi fundado este sindicato?

- Qual a finalidade e importância deste sindicato?

- Como é organizado este sindicato?

- De que forma ele atua na sociedade?

- Quais foram os principais movimentos políticos ou sociais que contaram com a participação deste sindicato?

- Como é a relação do sindicato com o governo?

- Qual é a influência que este sindicato exerce na instituição onde trabalham seus filiados?

- Quais foram as principais conquistas desse sindicato?

- Que benefícios sociais esses sindicatos garantem a seus filiados? 


\section{ANEXO III - QUESTIONÁRIO SOBRE OS TRABALHOS DE HISTORIA LOCAL DESENVOLVIDOS COM OS ALUNOS DA 2 a SÉRIE DO COLUNI NO ANO DE 2000.}

Marcar com um X as opções ahaixo, de acordo com o seu trabalho.

Nome

turma

1. O SEU GRUPO TRABALHOU O TEMA Imigrantes em Viçosa Partidos políticos em Viçosa Sindicatos em Viçosa Movimentos sociais da Igreja Sistema eleitoral

2. OS TEMAS ABORDADOS E O TIPO DE TRABALHO EM GERAL FORAM

Interessantes Chatos

3. ENTRE OS RECURSOS UTILIZADOS NOS TRABALHOS MARQUE OS QUE VOCÊ ACHOU MAIS INTERESSANTES (pode ser mais de um)

vídeo

entrevistas pesquisa bibliográfica fotografias cartazes teatralização 
4- O SEU TRABALHO E O DE SEUS COLEGAS ENRIQUECEU OS SEUS CONHECIMENTOS SOBRE A HISTÓRIA DE VIÇOSA, OU DE ALGUM MODO VALEU PARA VOCE

_ muito _ pouco _ muito pouco _ nada

JUSTIFIQUE

5. VOCÊ ACHA QUE ESSE TIPO DE TRABALHO DEVERIA SER APLICADO AOS ALUNOS DAS SEGUNDAS SÉRIES

$\operatorname{sim}$ não

Justificue

6- QUE CRÍTICAS VOCÊ APONTARIA AO TRABALHO SUGERIDO PELO PROFESSOR 